\title{
MAKING Up EXCITED DeLIRIUM ${ }^{1}$
}

\author{
SEANTEl ANAÏS
}

Abstract. This article examines the emergence of a medical condition increasingly cited as a cause of death in fatality inquiries in Canada: excited delirium. Beyond concerns arising from the association between excited delirium and police use of electrical weapons known as Tasers, one common concern about the medical condition is whether or not it is "real." Bypassing strictly realist or purely constructivist accounts, this article uses the conceptual language of historical ontology and science and technology studies to investigate how excited delirium is enacted in medico-legal sites. Contributing to sociologies of death and dying and category formation, it attends to the textually mediated practices of legal and medical experts in the United States and Canada that enact excited delirium as a coherent medical condition.

Keywords: excited delirium, death and dying, enactment, fatality inquiries, historical ontology, science and technology studies

Résumé. Cet article examine une condition médicale qui est de plus en plus citée en tant que cause de mort dans les enquêtes de fatalité au Canada: l'enthousiasme délirant. Outre les inquiétudes émergeant de l'association entre l'enthousiasme délirant et l'utilisation d'arme à impulsion électrique, connu sous le nom de "Taser", une des inquiétudes commune au sujet de cette condition médicale est de savoir si elle est "réelle" ou non. Contournant les théories du réalisme social strict ou du constructivisme pur, cet article utilise le langage conceptuel de l'ontologie historique et les études de science et de technologie pour examiner comment l'enthousiasme délirant est reconstitué sur les sites médico-légaux. Contribuant aux sociologies de la mort et du mourant et à la catégorie de formation, cet article adresse les pratiques textuellement négociées des experts médical et légal des États-Unis et du Canada qui décrète l'enthousiasme délirant une condition médicale cohérant.

Mots clés: l'enthousiasme délirant; mort et mourant; décrètement; enquêtes de fatalité; l'ontologie historique; études de science et technologie

1. Acknowledgements: Thanks are due to Bruce Curtis and Amelia Curran for their many insightful conversations concerning the processes through which "kinds" of people come into being. Gratitude is also due to Kevin Walby for his helpful suggestions on an early draft of the article and to the two anonymous reviewers from this journal, who provided invaluable critical engagement. 


\section{INTRODUCTION}

Theited delirium syndrome has been an object of expert reflection

Efor emergency-room doctors, epidemiologists, pathologists, and coroners in North America for the past decade. The American College of Emergency Physicians (ACEP 2009:1) describes the condition as a subcategory of delirium "described retrospectively in the medical examiner literature" which, over time "has made its way into the emergency medicine, psychiatric, law enforcement, prehospital, and medico-legal literature." According to the Report of the ACEP Task Force on Excited Delirium, patients suspected of having the syndrome present with a confluence of symptoms, including:

acute drug intoxication, often a history of mental illness (especially those involving paranoia), a struggle with law enforcement, physical or noxious chemical control measures or electrical control device (ECD) application, sudden and unexpected death, and an autopsy which fails to reveal a definite cause of death from trauma or natural disaster. (ACEP 2009:6)

Excited delirium has generated enough legal and governmental interest that a provincial court judge in the province of Alberta has called for the creation of a national database to track deaths attributed to it (Lamoureux 2011). At the same time, the ACEP Task Force notes that the term has been used to describe a "small group of patients with a set of symptoms that has eluded a unifying, prospective clinical definition" (2009:1). The indeterminacy of excited delirium makes the disease an intractable concern for medical and legal professionals.

While public controversy over excited delirium often centres on its purported causes, critiques raised by community activists and medical experts reflect concern about whether people are dying of excited delirium rather than excessive police force (Braidwood 2009). Excited delirium entered into the public and media lexicon around the time that increased use of electrical weapons ignited controversy in the United States, Canada, and the UK. As a result, both medical task forces and public inquiries into the connection between police use of force, excited delirium, and in-custody deaths have recurred throughout the past decade. The most extensive of these was the Braidwood Commission of 2008-2009. The inquiry was held subsequent to the death of Robert Dziekanski, a Polish traveller who became disoriented in the secure holding area of the Vancouver International Airport and died after four Royal Canadian Mounted Police officers deployed their electrical weapons in an attempt to subdue him. A bystander's video shows officers deploying their electrical weapons only seconds after arriving on the scene. The 
Braidwood Inquiry's task was to investigate the cause of Dziekanski's death and make recommendations for police use of electrical weapons. A number of medical and weapons-industry experts testified in support of the diagnostic value of excited delirium, yet several experts at the inquiry challenged the existence of the medical condition. ${ }^{2}$ While the Braidwood Inquiry disputed the medico-legal value of the diagnostic category, excited delirium is also cited as a cause of death in some provincial fatality inquiries. It continues to appear in police trade literature as well (Johnston 2012).

Such controversies fail to address the fact that even before doubts were raised about the existence of the condition, it took networks of legal and medical experts to make it real. Excited delirium, as an object of scientific and legal reflection, is enacted in a number of "medico-legal sites" (Harding and Adserballe 1983; Ward 1999; Prior 1987; McMullan 2007), two of which (the ACEP Task Force report, and provincial fatality inquiry reports) I examine below. ${ }^{3}$ In 2008 the Council of the American College of Emergency Physicians (ACEP) and its Board of Directors adopted Amended Resolution 21(08) to set in motion a study by a specially appointed task force -18 emergency room physicians and one $\mathrm{PhD}$ researcher - to determine if "the entity commonly referred to as 'excited delirium' exists" and "if so, whether it could be better defined, identified, and treated" (ACEP 2009:4). The resolution passed by the ACEP relates to a wider concern that excited delirium is a fabrication that draws public attention away from law enforcement in cases of incustody death. Individuals believed to have died as the result of sudden onset of excited delirium are typically involved in violent encounters with the police immediately prior to death. A number are shocked with electrical weapons (commonly known by the trade name Taser) in the moments before they die. Yet a number of ties bind "experts" on excited delirium to law enforcement agencies and/or the company that retains a monopoly on the manufacture and distribution of electrical weapons: Taser International. One member of the ACEP acknowledges in a sci-

2. Dziekanski's death was classified as a homicide by the British Columbia Coroner's service in the years subsequent to the Braidwood Inquiry. Multiple deployments of Tasers, along with the preceding altercation with police, were cited as factors by the coroner (Cullinane 2013).

3. Medico-legal sites are those in which the investigatory powers of medicine are marshaled to make claims with legal significance (Harding and Adserballe 1983; Prior 1987; Ward 1999; McMullan 2007). As medico-legal agencies, the American College of Emergency Physicians (ACEP) Task Force and the various provincial agencies conducting fatality inquiries use medical knowledge gleaned from research to make authoritative legal claims concerning causes of death and issues deemed to be of danger to the public. In the cases examined here, this medical knowledge emerges in legal contexts through expert testimony and the dissemination of official reports. 
entific journal that her medical research on excited delirium is funded primarily by the Canadian Association of Chiefs of Police (Hall 2009). Another member of the task force has acknowledged under oath at the Braidwood Inquiry that his funding for excited delirium research is provided by TASER International (Braidwood, 2009). As I examine below, three distinct discursive strategies are employed by medical experts and judges in building a general case for the existence of excited delirium and for its specific presence in the postmortem subject. First, the incorporation of law-enforcement accounts of the premortem scene; second, the attribution of controversy over the disease to more generalized difficulties associated with the classification and detection of disease; and third, by shifting the temporal frame of excited delirium to focus on efforts to identify the disease in a "premortem state" and effect early "therapeutic intervention" (ACEP 2009:4). I argue that as expert medical opinions on excited delirium are increasingly enmeshed in legal proceedings, attention is directed away from police use of force and towards speculation regarding the biomedical reality of the condition itself.

Law enforcement organizations and medical experts continue to claim that excited delirium constitutes a legitimate condition, while judicial officials wrestle with the issue of whether it should be cited as a cause of death. Both proponents of excited delirium syndrome and skeptical members of activist communities frame their concerns around the same question: is it a real biomedical condition? Limiting our engagement to this question misses a critical chance to assess the constitutive relations through which excited delirium is enacted. That is, we risk leaving unexamined the relations of practice and expertise that bring the medical condition into being. Consequently, it is important to describe how the operations of legal, medical, and state networks are organized in relation to the medical condition called excited delirium. To do this, I draw together three bodies of literature. First, sociologists of concept formation have mobilized the idea of historical ontology to examine the making up of categories that inform official responses to mental illness (see Hacking 1995, 2002; Davidson 2004; Ward 1997) and conduct deemed deviant or dangerous (Valentine 2007). Second, science and technology studies have emphasized the coordinated enterprise of humans and nonhumans (such as texts) in enacting scientific, legal, and social practices. Third, allied literature in the sociology of death and dying has focused on how investigations of mortality are carried out in medico-legal sites including mortuaries, government commissions, and modern statistical analyses (Prior 1987; Cradock 2007; Bayatrizi 2009). Drawing from these literatures, I trace the enactment of excited delirium 
in an American College of Emergency Physicians Task Force report and in provincial fatality inquiry (PFI) reports.

To examine how excited delirium is enacted within medico-legal sites I first draw from Ian Hacking's idea of historical ontology. Historical ontologists trace the emergence and trajectory of concepts with a focus on the constitutive relations that animate them - their interest lies not only in determining how things like diseases come into view but also how they shape future human conduct (Hacking 1995; Ward 1996; Davidson 2001; Sugarman 2009; Boone and Richardson 2010). Hacking coined the term making up people to name this process. Such analyses have demonstrated how identities have been constituted by the networks of relations that create, administer, and treat them. Among others, historical ontologists have studied the pathologized categories of multiple personality disorder (Hacking 1995), "war neurosis" (Boon and Richardson 2010), and homosexuality (Davidson 2001).

While historical ontology invites important attention to the construction of diagnostic categories and their relation to processes of identification, it is primarily concerned with the historical and social relations that animate the categories used to make sense of human experience and identity (Sugarman 2009). Thus, the focus is on how individuals and groups interact with the classifications that render them intelligible to medical and psychiatric experts. Rather than ask how individuals classified as excited deliriants conceive of themselves in relation to the classification, I ask how deaths are attributed to excited delirium and according to what forms of evidence; how diagnoses of excited delirium are inscribed in legal texts such as death certificates; how connections between the investigatory practices of medical and legal professionals are forged in shared zones of contact; and finally, how law enforcement professionals are trained to identify subjects who they believe may be suffering from excited delirium. To supplement historical ontology, I draw from science and technology studies and their focus on nonhuman actors including texts (Latour 2005). Scholarly work situated in STS provides a set of useful tools for examining the material processes according to which bodies and their pathologies are brought into being (Mol 2002). From an STS perspective, disease conditions are not "constructed" so much as they are the material and practical congealment of ongoing enactments staged in medico-legal contexts. The questions of whether they are "real" or not, from the point of view of STS scholarship, would detract attention from the material relations through which they are made real. The real is an ongoing enactment. STS adds a material focus to historical ontology that is necessary for studying how conditions like excited delirium come into being over time, and for focusing on how various agencies are enrolled 
into the ongoing process of enacting them through institutional practices. Together they provide a framework for understanding how sites of legal and medical knowledge production account for suspicious deaths.

Official task forces and coroner's inquests were chosen as case studies because they are specific and related sites for the contemporary enactment of excited delirium. Here I analyze a set of texts circulating within and between two distinct sites: provincial coroner's inquest reports (also known in Canada as provincial fatality inquiry reports - hereafter PFI reports) involving a posthumous diagnosis of excited delirium from 2002-2012 and the ACEP Task Force inquiry into the existence of excited delirium as a disease entity. Documents were analyzed to assess how various actors justified their views concerning the existence of excited delirium. Prior (2008:822) has recently argued that while "social research documents tend to enter and to leave the "field' in relative silence," they ought to be studied as active components of knowledge networks. Texts connect and coordinate the situated knowledge of dispersed medical and legal sites with one another - they coordinate disparate fields of expertise that coalesce around medical conditions. Texts also contribute to wider efforts to recruit and mobilize allies within and between medical and legal fields to form a network of expertise that engages in an ongoing project to transform excited delirium from an obscure object into a legitimate medical diagnosis.

\section{THE ACEP TASK ForCE}

The claim that psychological and medical concepts are constructed is not novel (Hacking 1995). Yet as Ward (1996) suggests, existing accounts are often imprecise when describing the relations that enact a stable social construct. In this section, I examine one of the sites where efforts to stabilize the concept of excited delirium coalesced: the ACEP Task Force Report on Excited Delirium. The report of the ACEP Task Force attempts to place the syndrome in a historical context, noting that the symptom clusters known as excited delirium today appeared in the medical literature over 150 years ago. These cases occurred primarily "within institutions that house mentally disturbed individuals in protective custody largely because of the lack of effective pharmacologic treatment available during that time period" (ACEP 2009:5). Dr Luther Bell was the first to describe the deadly clinical condition that recurred at the McLane Asylum for the Insane in Massachusetts. The Task Force report authors suggest that "Bell's Mania may be related to the syndrome of [excited delirium] that we witness today" (ACEP 2009:5). The authors 
attribute a dramatic increase in the number of reported cases of excited delirium with "behaviour similar to an uncontrolled psychiatric emergency" in the 1980 s, noting that most of these cases were found to be associated with "the introduction and abuse of cocaine in North America" (2009:5). While excited delirium is constituted in the ACEP report as a medical condition with a history and observable specificity, it is also argued that excited delirium is indeterminate. This indeterminacy is not acknowledged to be a threat to the medical condition's existence, but is positioned as either an essential characteristic of the condition or the result of failures by police and medical practitioners to detect its presence.

Like many medical conditions, excited delirium offers new possibilities in thinking of human conduct (Hacking 1995, 2002). While historical ontology offers a framework for understanding how new classifications delimit new forms of human possibility, some sociologists have noted that it leaves the practical aspects of classification unexamined (see Valentine 2007). Others suggest that while Hacking (1998) addresses the question of how disorders achieve ontological stability and become objects of professional classification and public concern, historical ontology is not primarily focused on determining why some classifications make their way into lay and professional lexicons while others do not (for example, see Ward 1997).. At any rate, historical ontology does not emphasize the mundane textual activities involved in circulating a concept with enough force to effect change in the ways that some lives — and deaths - are made sense of. In Hacking's (1995) account, a central component of "making up people" is the "looping effect of human kinds." This looping effect names a process whereby "people classified in a certain way tend to grow into the ways that they are described; but they also evolve in their own ways," so that the coordinates of existing schemata of classification and description are constantly being replotted (Hacking 1995:21). Excited delirium produces looping effects of a different kind, where organizations such as emergency physician's professional associations and law enforcement agencies recalibrate their schemes of classification to accommodate changes in the enactment of excited delirium.These efforts stabilize excited delirium as a medical condition and define new possibilities for human existence at the moment that human life has ceased.

The indeterminacy of excited delirium draws attention not only to the biological relations of disease but towards the social relations that animate illness. The authors of the ACEP report attempt to manage the indeterminacy of excited delirium in three distinct ways: first, by relying on descriptions of the premortem scene from the perspective of law enforcement officers; second, by locating controversies over the disease 
within the context of difficulties associated with the classification and detection of disease rather than generalized uncertainty over the existence of the syndrome; and third, by shifting the temporal frame of excited delirium so that the objective of future research and the raising of awareness about the disease is to make it possible for police officers, emergency first responders, and medical personnel to identify the disease in a "premortem state" and to effect early "therapeutic intervention" (ACEP 2009:4) rather than in a postmortem setting.

Excited delirium syndrome is similar to a number of disease objects such as fatal child abuse and sudden infant death syndrome - it is constituted at intersections between socio-legal and medico-biological fields (see Cradock 2011). The authors of the ACEP report note that the syntactical decision bearing on excited delirium's classification as a syndrome rather than a disease is related to the "lack of a clear definition and cause" along the lines of the "decades-long controversy over the causes of Sudden Infant Death Syndrome" (2009:4-5). The report speaks to the extent to which the investigatory powers of the police are marshaled in service of growing medical knowledge of the syndrome: "over a two-year period, [the] presence or absence of 10 potential clinical features of ExDS was recorded by Canadian police for over 1 million police-public interactions" (2009:7). The task force underwrites the reality of the excited delirium by intermingling the explanatory powers of scientific medicine with the anecdotal accounts of police, revealing how medical and epidemiological knowledge of the medical condition is grounded in social rather than strictly clinical concerns.

The Task Force has argued that ExDs is typified by the "presence of a distinctive group of clinical and behavioral characteristics that can be recognized in the pre-mortem state" (2009:4). Though there is "little documentation about survivors of the syndrome ... some Task Force members have cared for multiple individual patients with ExDS who have survived" (2009:6). The authors list a number characteristics of excited delirium based on law enforcement descriptions of premortem scenes: "hyperaggressiveness with bizarre behavior, imperviousness to pain, and combativeness ... typically a struggle with law enforcement that involves physical [force], noxious chemical, or ECD use followed by a period of quiet and sudden death" (2009:6). Thus excited delirium is a syndrome with biomedical as well as social specificity: it describes individuals who are aggressive, exhibit bizarre behaviour, seem to be unaffected by pain, and have had recent contact with police. Yet the authors acknowledge that they "do not fully understand why some cases progress to death and why some do not" (2009:6). 
The report reserves a special section for the role of law enforcement in premortem descriptions of the disease, noting that police are in the "difficult and sometimes impossible position of having to recognize this as a medical emergency" while attempting to establish control over an "irrational and physically resistive person" (2009:8). When excited deliriants are characterized as "irrational," "drug users," without "remorse" or "normal fear and understanding of surroundings" and "persons with psychiatric illness," there is little space for recognition of police use of force. Such descriptions of the premortem scene by law enforcement officers appear in a report drafted by medical experts as part of an attempt to stabilize the syndrome as a determinate biological condition. Advocates of excited delirium — in policing and medical professions — thus form part of a network of action that constitutes the syndrome as a stable disease entity. These descriptions - and the textual practices that stage encounters between medical and legal professionals - are not passive. They make practical and material differences in the world in the sense that they influence how deaths are classified after use-of-force incidents and they lend support to the notion that death from excited delirium is possible and likely.

The second way that the authors of the ACEP Task Force report manage the indeterminacy of excited delirium is by framing its instability as an effect of the inherent difficulty associated with the classification and detection of all disease entities. The difficulty surrounding the clinical identification of excited delirium "is that the spectrum of behaviors and signs overlap with many clinical disease processes" (2009:5). By troubling the possibility of easy detection and classification, the authors of the report downplay suspicions that excited delirium is not something "out there" waiting to be discovered by the astute clinician. As the authors put it, the "issue of semantics does not indicate that ExDS does not exist" (2009:6, italics applied). Task Force efforts at stabilizing the condition as a coherent medical entity are directed at those who "believe it to be a convenient term used to exonerate authorities when someone dies ... in custody" (2009:6), and the authors dismiss opponents who believe that excited delirium is a concept that has been created "as a law enforcement conspiracy or cover-up for brutality" (2009:6).

The issue of classification and detection is confounded by the presence of underlying medical conditions that are said to generate excited delirium: "as in any disorder that affects mental status, there is no assumption that each subject's presentation will occur as a completely discrete entity with absolute boundaries" (2009:10). The presence of law enforcement is identified as a further confounding factor. When deaths occur in custody, there exists the "additional difficulty of separating any 
potential contribution of control measures from the underlying pathology" (2009:17). This underlying pathology has not yet been specified, owing to the lack of a large "epidemiologic prospective study," a "national or international database of all suspected cases," and - at a molecular level - a "Genome Wide Association Scan" to identify "susceptibility genes" (2009:17). In this way, the authors of the report locate difficulties in stabilizing the disease in relation to the absence of sophisticated detection tools - seemingly reliable means of ascertaining the biological reality of the medical condition.

Finally, the ACEP report authors manage instability by shifting the temporal relations of excited delirium. The claim that excited delirium is a distinct group of "clinical and behavioral characteristics" hinges on the assertion that it can be "recognized in the pre-mortem state" (2009:4). The report acknowledges that the temporal relations of excited delirium are problematic: "until wider recognition of ExDS began, most publications about it were found in the forensic pathology literature and there was little publication interest in cases of ExDS that did not end catastrophically" (2009:10). Whereas the bulk of excited delirium diagnoses are enacted in postmortem pathology labs, the authors note that in the future, there "might be found a genetic susceptibility, an enzyme excess or deficiency, and overdose or withdrawal state, or some other multifactorial trigger" (2009:5) which would shift the temporal frame of diagnosis back across the divide between life and death. To that end, the authors recommend that "prehospital ExDS" should be presumed in subjects "displaying 6 or more" of the 10 features of excited delirium (2009:12). Claims that "some Task Force members have cared for multiple individual patients with ExDS who have survived" (2009:6) suggest that the condition is an observable premortem reality and not simply a "diagnosis of exclusion established on autopsy" (2009:6).

The authors note that it is the responsibility of police and emergency first responders to recognize the early signs of excited delirium to avoid fatal outcomes. When dealing with a possible case of excited delirium, the report proposes that police should attempt to document the tactile temperature of these subjects and "request EMS to measure it" (2009:9). An elevated temperature may suggest that a "life-threatening disease or condition was present, and that the death was independent of the police intervention" (2009:9). This recommendation rearranges the temporal relations of excited delirium, making it possible to establish a link between the fatality and the syndrome and to exclude police use of force as a precipitating factor. This is in contrast to the earlier suggestion in the report that "the majority of lethal ExDS patients die shortly after a violent struggle" (2009:8) and it leaves unacknowledged that the cluster of 
symptoms associated with excited delirium is derived mainly from law enforcement descriptions of the premortem scene rather than biomedical data.

The enactment of excited delirium in the medico-legal site of the ACEP Task Force report is illustrative of the labour that goes into stabilizing excited delirium as a legitimate diagnostic category. This stabilization takes several forms. First, the descriptions made law enforcement personnel lend the disease some specificity. While the report attempts to provide a medical definition of the disease with a basis in scientific data, it also relies on written police descriptions of the social lives of subjects suspected to have excited delirium. Second, the report attempts to index controversies over the existence of excited delirium to the mundane difficulties associated with any classificatory scheme. The attendant challenges of classifying excited delirium are normalized to make them seem part of any new diagnostic classification rather than a feature of the fragility of the concept itself. Third, one of the strategies employed by the authors of the report is to shift the temporal character of excited delirium to suggest that it presents an observable regularity outside of the forensic pathology lab. Of course, without an "identifiable pathophysiology" (2009:5), the condition does not even present an observable regularity inside the pathology lab.

STS accounts offer a way of thinking through the ways in which such "differences in medicine" are managed (Berg and Mol 1998). For example, lung cancer cases present a pattern of observable regularity in pre- and postmortem states. It is possible to point to a lung mass on an $\mathrm{x}$-ray in a premortem setting and if interventions fail, it is possible to locate a postmortem lung mass in a pathology lab. Scholars of science and technology have pointed out that different settings and diagnostic tools produce multiple enactments of medical conditions rather than different perspectives on the same disease object (Mol 2002; Law and Singleton 2005). The differences that persist between lung cancer as it is enacted in the x-ray lab and as it appears in a pathologist's examination suggest multiple enactments of lung cancer that cannot be reduced to difference in perspective. Excited delirium is similarly multiple. The difference between it and disease entities like lung cancer is that it has never been observed as an emergent feature of the body and its constituent tissues. This is not acknowledged to be an effect of multiple enactments of the condition. Instead, it is characterized as a failure to detect the "identifiable pathophysiology" of excited delirium - a failure to find what is assumed to be there. The multiplicity of excited delirium emerges as an effect of the many enactments of the condition performed across textually mediated medico-legal sites: they conspire to consolidate the 
impression that the condition can be identified in premortem states and retroactively recognized after a death has occurred. Neither enactment is less real than the other, but each represents a distinct performance of disease by drawing on specific networks of relations to make them visible and actionable. Enacted through textual practices in these various medical and legal sites, excited delirium has consequences for the ways subjects live and die and for the ways their living and dying are made to count. Next, I explore how excited delirium is made in fatality inquiry reports. Fatality inquiry reports enact excited delirium and create a space of possibility for human conduct by constructing the historical conditions within which a particular "human kind" emerges (Hacking 2002).

\section{FATALITY INQUIRY REPORTS}

In Canada, fatality inquiries and coroner's inquests fall under provincial jurisdiction, a situation further confused by some provinces' adoption of the medical examiner's model over the coroner's model. In both models, inquiries are held and a report is written. Inquests are formal legal proceedings involving expert and eyewitness testimony as well as small juries in some cases. The aim is to review the circumstances of an unnatural death and to ascertain the facts surrounding the death rather than to attribute fault of guilt to any particular actor. Moreover, they are accountability mechanisms to determine the truth of tragic events and they are mandated to formulate recommendations on how provincial and federal government agencies should act to avoid damage to the public interest and their credibility. In most provinces and territories in Canada an inquest is mandatory - pursuant to the relevant fatality inquiries acts - if the deceased was in the care or control of a police officer or in custodial detention at the time of death.

Fatality inquiries and coroner's inquests are contact zones that connect experts in the networks that enact excited delirium. Their reports reveal how experts work to create a singular interpretation when multiple points of view are brought to bear on a single event. They demonstrate how texts mediate attempts to think about and act on the problems that coroners and medical examiners are responsible for assessing. Finally, they show how certain social problems coalesce into legal and medical domains of inquiry focused on the production of an official account to be disseminated to the waiting public who distrust government agencies. Provincial fatality inquiry reports begin with a formulary in the familiar style of a decree: it includes the pertinent details of the inquiry, information about the time and place of death, name of the deceased, and the findings as they regard manner and cause of death. A detailed report fol- 
lows the first page. Fatality inquiry reports are significant because they are part of a network of practice that includes human and nonhuman actors that enact forms of human subjectivity (Prior 2008). In this case, they bring excited delirium into being, making it possible for one's death to be classified, described, and accounted for in particular ways.

In social studies of science and technology, disease objects "can be detected only in a network of relations that make them visible" (Law and Singleton 2005:336). While a number of scholars have described those networks of relations in ethnographic detail in laboratories, few have sought to locate the specificity of relational networks in the context of law. Social inquiries into science and technology have acknowledged that disease conditions depend on the networks established within and between the "laboratory tests, for instance radiological, histological, physiological and/or behavior that secure their identification - and indeed their reality" (2005:336). Excited delirium depends on a similarly complex set of medical and legal networks to secure its identification. Legal and medical networks must work together to stabilize indeterminate disease entities. As Law and Singleton (2005:337) put it, "it takes effort to sustain stable networks of relations." The disease objects that interest them "have to be maintained if they are to sustain themselves and move between locations. Otherwise, things start to lose their shape, lose their characteristics and seep away" (2005:337). Here I discuss two fatality inquiry reports from the province of Alberta, Canada based on investigations into the in-custody deaths of Ted James Meiorin in 2006 (Bast 2007) and Gordon Bowe in 2008 (Lamoureux 2011). The reports show how excited delirium is enacted in distinct medico-legal sites, in this case between the investigative network of medical and legal experts that coalesce to form a provincial fatality inquiry (PFI) in Canada and the network of medical experts belonging to the ACEP in the US. The existence of excited delirium was not only acknowledged by the presiding judges but was named as cause of death in each case (Lamoureux 2011:1; Bast 2007:1).

Each PFI report acts as a distinct site for the enactment of the syndrome. The same three strategies present in the ACEP report for managing the indeterminacy of excited delirium were employed in the inquiry reports. Law enforcement and lay-witness descriptions of the premortem scene play into decisions to attribute a death to excited delirium. More general challenges associated with classifying and describing death tend to obscure questions regarding the ontological status of excited delirium. The recommendations of each inquiry reflect a concern with the temporal relations of excited delirium. Like the ACEP report, the fatal- 
ity inquiry reports suggest that one of the major problems with excited delirium is that its presence is not recognized early enough.

A number of sociologists of death and dying have located their inquiries at the nexus between death and the socio-legal sites where concerted efforts are made to make sense of it and to enter it into the public record. For example, Prior (1987) has written on the mortuary, while Bayatrizi (2009:613) has shown how statistical practices aimed at enumerating death have underpinned the organized study of the "aggregate dimensions of social life." As legal sites, fatality inquiries draw on a complex network of relationships and forms of knowledge: the legal knowledge of the presiding judge; the lay knowledge of jury members; the medical knowledge of the coroner, medical examiner, and expert witnesses. Both the Meiorin and Bowe PFI reports include expert testimony from one of the ACEP Task Force Members, Dr. Christine Hall, who travels within and between the sites where the syndrome is enacted, sharing information and lending her expertise. Both reports also include cocaine in the cause of death findings: each man's death was classified as "cocaineinduced excited delirium." While cocaine was found to be an underlying factor in each death, the pathological evidence would not support a cause of death finding of cocaine overdose to the exclusion of other factors. This is consistent with the ACEP report, which notes that excited delirium may be accompanied by a number of factors related to drug use and underlying mental illness but that it is a "unique syndrome" (2009:4).

Fatality inquiries are grounded in social rather than medical or scientific concerns (Prior 1987); they rely on lay-witness renderings of the scene and the opinions and feelings of witnesses; and they incorporate a vast array of knowledge that is neither legal nor medical. While the finding of cause of death is based on a forensic pathology exam, the final report of the inquiry incorporates testimony from lay witnesses and law enforcement personnel. In the PFI into the death of Howard Bowe, Rick Smith, a co-director and co-founder of Taser International - who has not trained or qualified as a medical doctor — testified that it was his view that there "is no evidence that the Taser causes cardiac arrhythmia in human subjects" (Lamoureux 2011:4). The fatality inquiries into the deaths of Meiorin and Bowe demonstrate that, just as in the ACEP report, law enforcement descriptions of the premortem scene play an important role in the enactment of excited delirium. In the case of Meiorin, the subject was said to be "clad only in boxer shorts and foaming at the mouth" (Bast 2007), while Bowe was "observed on his back with a fist clenched making grunting gurgling sounds" and was discovered "jumping from one room to the other with eight-foot jumps ... and yelling unintelligible words" (Lamoureux 2011:2). The descriptions of the 
premortem scene offered by law-enforcement officers ascribe the subjects with certain social attributes: Bowe was characterized as "suspicious," "yelling unintelligible words," and possibly "under the influence of drugs" (2011:7). Officer Barrett, one of the officers who attended the scene in Bowe's case observed that he was "incredibly strong" (2011:2). Similarly, "unusual strength" is regularly included in the symptom cluster of excited delirium (e.g., ACEP 2009:7), which fits in with the consistent observation that arrests of excited deliriants require use of police force. It is the unusual strength of excited deliriants that is believed to necessitate extreme force, but unlike the medical condition of excited delirium, extreme police use of force was never put forward as a possible cause of death in either case. The incredible strength of Howard Bowe is described in the following excerpt from the PFI report:

It took four police officers administering various police actions [including the Taser] and commands to bring Mr Bowe into position of control [sic]. In fact, the body weight of four persons were on $\mathrm{Mr}$ Bowe at the point of cuffing. At this time, that is the time of cuffing, Mr Bowe was grunting, snorting and breathing heavily ... within minutes, Mr Bowe became unresponsive and EMS was called in.

These scenes, which involve a confluence of physical descriptions of the medical condition of the deceased, do not constitute medical evidence. For example, Justice Bast notes in the PFI report that "Mr Meiorin was a short, over-weight man who had a history of asthma" - although the question of overweight and asthma were never raised in the inquiry by the medical professionals who gave evidence. These attributions establish for the inquiry a picture of what kind of person the deceased was in life: the evidence given by Constable Van Tassel and Officer Stewart, which corresponded with observations made by other law enforcement personnel in attendance, characterized Bowe as "irrational" and "aggressive" (Lamoureux 2011:2). Justice Bast noted in his fatality inquiry report that "by all accounts ... Mr Meiorin was agitated, inappropriately clothed, breathing heavily, sweating, and foaming at the mouth. He was oblivious to those around him and was talking gibberish..." (Bast 2007:4). Both deceased were found to be drug users, although their drug use was not found in either case to be the sole cause of death (Bast 2007:4; Lamoureux 2011:1). For proponents of the syndrome, these attributions bolster the case for a finding of death caused by excited delirium.

Excited delirium is further enacted as a stable disease object in the PFI through a focus on the difficulty of determining a single cause of death. Whereas the ACEP stabilizes excited delirium through a discus- 
sion of the difficulties associated with classifying and describing pathology, the PFI reports reveal how such challenges play out. Bast's PFI report notes that the autopsy performed on Meiorin "found nothing which could explain [his] death" but that the toxicological examination found that the "concentration of cocaine found in Mr Meiorin's system was high enough to be the cause of death" (2007:4). The Chief Medical Examiner of Alberta gave evidence that the trigger for the onset of excited delirium was the high level of cocaine in Meiorin's system and found that the cause of his death was the "'excited delirium,' not the [police] restraint" (Bast 2007:4). Alternative possible causes of excited delirium are naturalized as part of the warp and weft of every sudden death involving a dramatic police-citizen encounter and a cluster of attendant factors. The factors surrounding excited delirium deaths given in evidence by Dr. Hall are identical to those in the ACEP report (Bast 2007:5). In the PFI report on the death of Howard Bowe, the judge notes that

Dr. Hall was also asked whether the physical struggle with the police exacerbated the progress of Mr. Bowe's medical condition - Excited Delirium ... researchers do not know exactly what the tipping point is in the physical struggle with the police in terms of the progress of Excited Delirium. (Lamoureux 2011:4)

Just as in the ACEP report, both PFI reports note the difficulty inherent in detecting and classifying disease. Thus, the limitations faced by medical and law enforcement personnel in identifying excited delirium, and the challenges associated with "furthering medical knowledge in this area" are the focus of inquiry recommendations. Dr. Hall noted in her testimony that "the Canadian Association of Chiefs of Police could assist $\ldots$ in this area through a national endorsement of the study known as RESTRAINT" (Lamoureux 2011:5). ${ }^{4}$

Finally, the PFI reports stabilize the concept of excited delirium by shifting its temporal relations. Both reports acknowledge that excited delirium should be recognized by police and emergency personnel earlier in its progression to avoid tragic consequences. This is a means of managing the indeterminacy of a medical condition that is predominately identified after death. The inquiry report dealing with the death of Howard Bowe recommended that call-takers and dispatchers "providing

4. An author bio in the Canadian Journal of Emergency Medicine notes that Dr. Hall is "the principal investigator of the RESTRAINT Study, a prospective, multicentre study of persons undergoing police restraint and of the SCAPGAS Study, which seeks to determine whether an alternate method for the procurement of capillary blood gases can be developed for use in agitated, combative and often handcuffed patients in the prehospital setting. Funding for both these studies was provided by the Canadian Police Research Centre" (Hall 2009:86). 
services to police agencies in Alberta receive updated training on the identification and management of potential Excited Delirium incidents ... [and that the] training be mandatory for all existing and newly hired staff" (2011:5). This shifts the temporal character of excited delirium from one of a postmortem diagnosis to a condition with a clearly identifiable symptomatology before a fatal progression. As Judge Lamoureux puts it in the PFI report, calls to emergency dispatch "often clearly point to the fact that the subject may be in a state of ExD" (2011:5). These recommendations are aimed at generating actionable data on excited delirium "upon which the Canadian Police Chiefs could conduct research" (Lamoureux 2011:6), and suggest that the condition would be recognized more often if awareness were raised and the proper tools of detection were disseminated.

While "making up people" names a set of practices whereby kinds of (human) being are created, the focus has not generally been on how these processes operate to enact new postmortem identities. Untangling the processes through which classifications and new human kinds are made up requires recognition of the collective work of human and nonhuman actors and the textually mediated labour inhered in networks of action. If provincial fatality inquiries in Canada and task force reports in the US contribute to the enactment of particular realities, then it is important to attend to the strategies that they use. The relative stability of the concept of excited delirium in the PFI is achieved according to the same three strategies that collude to stabilize the medical condition in the ACEP report. The fatality inquiries rely on the descriptions of law enforcement personnel pertaining to the premortem scene, and enmeshed in these descriptions are a number of judgments concerning the social lives and histories of the deceased. The testimony given by these experts, similar to the conclusions reached in the ACEP report, locate the indeterminacy of excited delirium in relation to generalized difficulties associated with the detection and classification of disease. The ultimate recommendation of the fatality inquiries to establish protocol for recognizing, tracking, and treating the medical condition before a fatal progression lends strength to the notion that excited delirium is a "real" entity, and that lives could be saved if law enforcement, first responders, and emergency medical personnel could recognize it in time.

\section{Conclusion}

Excited delirium is being enacted in numerous sites across North America: in public and professional education campaigns, at law enforcement trade shows, and in public commissions of inquiry into in-custody death 
(Braidwood 2009). These places also serve as sites where excited delirium falls apart, where the constitutive relations that hold it together no longer do so effectively, and where competing knowledge networks manage to destabilize the concept so that it no longer offers a viable way of making sense of death. We risk overlooking the complex nature of these distributed enactments when we simply focus on the question of whether excited delirium exists. Questions that attempt to determine the reality of a particular disease entity tend not to address more mundane and troubling questions, namely: how is excited delirium enacted? What are the conditions of its possibility? What spaces of human possibility does it in turn open up? And where is it produced?

Drawing on the theoretical insights of Ian Hacking, I suggest the important question is not only how diseases come into view, but how they create new possibilities for the ways that human kinds come into being. The case of excited delirium adds an important layer to these concerns because it alters collective understandings of death and dying. Some means of classifying death have a way of discounting the value of a life.

Drawing on science and technology studies, I have focused on the texts that form investigative task forces and provincial fatality inquiries as medico-legal sites. In tracing the textual practices germane to these sites of legal inquiry, I have drawn attention to the practices through which excited delirium has emerged and been made visible. A combination of the conceptual language of historical ontology and science and technology studies are important tools for tracing the material and textual relations that attempt to settle public contestations by validating expert knowledge and lay testimony as appropriate contributions to legal and medical knowledge. Law and Singleton (2005) note that the consistent enactment of constitutive relations is required if objects are to be sustained and move between locations. Nothing, they argue, is "fixed and forever ... only some things are fixed, and for a time" (2005:337). On April 9, 2013, the British Columbia Coroner's Service issued a statement to media. Nearly six years after the events that unfolded at the Vancouver International Airport, the cause of Robert Dziekanski's death is acknowledged to be cardiac arrhythmia complicated by a police altercation. Having found "no natural disease process that would have likely led to sudden death," the findings of the recent provincial fatality inquiry reinscribe Dziekanski's death into the official record as a homicide. An appreciation of the emergence of medical conditions and the interventions and inscriptions that they engender should involve full attention to the practices that constitute them. Attending to the seemingly ordinary practices through which things like excited delirium are enacted may ultimately help us to consider how they might be made to fall apart. Indeed, it follows that a political project 
of making things fall apart would require a similarly sustained and dedicated network of (counter)constitutive relations.

\section{REFERENCES}

American College of Emergency Physicians (ACEP). 2009. White Paper Report on Excited Delirium Syndrome. Report to the Council and Board of Directors on Excited Delirium at the Direction of Amended Resolution 21(08): np.

Bast, Monica. 2007. Public fatality inquiry into the death of Ted James Meiorin. Report to the Minister of Justice and Attorney General, Edmonton, Alberta.

Bayatrizi, Zoreh. 2009. Counting the dead and regulating the living: Early modern statistics and the formation of the sociological imagination (16621897). British Journal of Sociology 60(3):603-621.

Berg, Marc and Annemarie Mol, eds.1998. Differences in Medicine: Unravelling Practices, Techniques and Bodies. Durham, NC: Duke University Press.

Boone Katherine and Frank Richardson. 2010. War neurosis: A cultural historical and theoretical inquiry. Journal of Theoretical and Philosophical Psychology 30(2):109-121.

Braidwood, Thomas. 2009. Restoring public confidence: Restricting the use of conducted energy weapons. Victoria, BC.

CBC Online. 2013. Dziekanski death at hands of RCMP a homicide, B.C. coroner rules. Accessed 8 April 2013 from http://www.cbc.ca/news/canada/calgary/story/2013/04/08/bc-dziekanski-coroners-report-homocide. $\underline{\mathrm{html}}$.

Cradock, Gerald. 2011. Thinking Goudge: Fatal child abuse and the problem of uncertainty. Current Sociology 59(3):362-378.

Davidson, Arnold. 2004. The Emergence of Sexuality: Historical Epistemology and the Emergence of Concepts. Cambridge, MA: Harvard University Press.

Hacking, Ian. 1998. Mad Travellers: Reflections on Transient Mental Illness. Charlottesville, VA: University of Virginia Press, 1995. Rewriting the Soul: Multiple Personality and the Science of Memory. Princeton, NJ: Princeton University Press. 2002. Historical Ontology. Cambridge, MA: Harvard University Press.

Hall, Christine. 2009. Public risk from tasers: Unacceptably high or low enough to accept? Canadian Journal of Emergency Medicine 11(1):84-6.

Harding, T.W. and H. Adserballe. 1983. A summary of results from a WHO coordinated study. International Journal of Law and Psychiatry 6:391-398.

Johnston, Joel. 2012. Stop the madness: Excited Delirium does exist. Blue Line: Canada's National Enforcement Magazine: March. 
Lamoureux, Heather. 2011. Public fatality inquiry into the death of Howard Bowe. Report to the Minister of Justice and Attorney General, Edmonton, Alberta.

Latour, Bruno and Steve Woolgar. 1986. Laboratory Life: The Construction of Scientific Facts. Second edition. Princeton, NJ: Princeton University Press.

Latour, Bruno. 2005. Reassembling the Social: An Introduction to Actor-network Theory. Oxford: Oxford University Press.

Law, John and Vicky Singleton. 2005. Object lessons. Organization 12(3):331355.

McMullan, John. 2007. Lost lives at Westray: Official discourse, public truth and controversial death. Canadian Journal of Law and Society. 22(1): 21-42.

Mol Annemarie. 2002. The Body Multiple: Ontology in Medical Practice. Durham, NC: Duke University Press.

Prior, Lindsay. 1987. Policing the dead: A sociology of the mortuary. Sociology 21(3):355-376.

2008. Repositioning documents in social research. Sociology 42(5):821836.

Sugarman, Jeff. 2009. Historical ontology and psychological description. Journal of Theoretical and Philosophical Psychology 29(1):5-15.

Valentine, Kylie. 2007. Methadone maintenance and making up people. Sociology 41(3):497-514.

Ward, Steven. 1996. Filling the world with self-esteem: A social history of truthmaking. Canadian Journal of Sociology 21(1):1-23.

Ward, Tony. 1999. The sad subject of infanticide: Law, medicine, and child murder, 1860-1938. Social \& Legal Studies 8(2):163-180.

Seantel Anaïs is an Assistant Professor in the Department of Sociology at the University of Victoria. Her research program focuses on critical security studies and critical socio-legal studies. Her two ongoing projects examine the materialities of Cold War sites of security and their recent transformations and mass litigation in war materiel contamination cases, respectively. Articles have recently appeared in Deviant Behavior, Security Dialogue, Critical Discourse Studies, and the Canadian Journal of Law and Society.

sanais@uvic.ca 